\title{
Correspondence
}

\section{"DERMATOLOGIC MISNOMERS"}

To the Editor:- In an interesting article in the February number of this journal Dr. Moses Scholz discusses dermatologic misnomers. I agree with him as to the impropriety of many of these names and share his dislike for them, but it is always difficult and often inadvisab'e to change a name in common use however bad it may be. Erasmus Wilson, a classical scholar, gave excellent reasons for a change of certain dermatologic names, but the change only produced confusion. Jonathan Hutchinson introduced a few new names which proved too objectionable to become generally adopted. I, myself, must confess to having urged certain changes of name for which I am now sorry, but I am g'ad of a partial success in substituting trichophytosis for tinea trichophytina, chromophytosis for tinea or pityriasis versicolor (which Dr. Scholz would call tinea furfuracea microsporina), fibroma for molluscum fibrosum, and nodular syphilid for the old term tubercular syphilid. I still contend that the shorter and perhaps more meaningless a name is, the better. When a name embodies a partial description of a disease it is very apt to be too long and cumbrous and when our views of the disease undergo a change, as often happens, the name too must be remodeled. The name yaws fulfills the purpose of indicating a disease that few of us have seen but of which we have a definite mental picture. The name means nothing to us, and if we knew its origin and significance we might deem it highly inappropriate. A meaningless name never becones a misnomer.

An attempt to change some of the names mentioned would only result in useless argumentation. As to the name erythema, it means more than hyperemia. It implies simple hyperemia in some cases and exudation in others. Dr. Scholz asserts that no condition showing exudation can be termed erythema. As a matter of fact, it not only can be so termed but has been so termed by great and good dermatologists of the past and present. When the skin becomes swollen and hard and presents certain clinical features the name erythema induratum, first applied to the condition by Bazin and now well established, very few would regard as a "most glaring dermatologic misnomer."

If erythema nodulare is an "equally untenable name," why does Dr. Scholz use it? I never heard of it before and do not find it in the index of recent dermatologic textbooks. The question is asked "For want of a hetter name why not call erythema multiforme dermatosis multiforme?" One answer is easy: Because the name suggested is ungrammatical. Dermatosis is a feminine noun and its adjective should be multiformis. Other valid answers might be given and a great difference of opinion elicited as to the propriety of changing many of these alleged misnomers.

The name eczema, which it is claimed should be discarded or changed to dermatitis, has now been in use for over two thousand years, and I venture to predict that this "time honored but vague term" will remain in use for centuries after Dr. Scholz and I have lost our interest in dermatology. It has always meant something, and it would be better now to strictly define its meaning than to change it for another name which would as readily be misunderstood. Our vague conception of eczema is our own fault and not the fault of the name. 
And now to change the subject, let me say that far more regrettable than misnomers is the careless manner in which many of us express our dermatologic ideas. Would that every contributor to the ARCHIVES might read Duhring and Morrow carefully, not only to become familiar with their views but to acquire, if possible, their clear, concise and beautiful diction.

We are all prone to write hastily and some of us seem disposed to bury our ideas in a mass of high sounding verbiage which may impress but does not enlighten the reader. A blue pencil cannot be used too freely in going over manuscript intended for the printer. For example, Dr. Scholz says: "The very fact of redundancy and superabundance of dermatological nomenclature so often commented on and lamented about, can be utilized for the purpose of selection of more correct and better fitting names." $\mathrm{He}$ might have said that the oft lamented abundance of dermatologic names can be utilized in selecting those most fitting and have expressed the idea more clearly and in just half the number of words. In mentioning the claim that dermatitis is local and eczema of systemic origin, Dr. Scholz says: "The mere difference of etiology could warrant only a separation of idiopathic eczemas from specific eczemas and idiopathic dermatitides from specific dermatitides, but it does not justify the creation of two separate clinical entities to express merely the difference of etiology in otherwise identical conditions." This and other sentences written with fewer and simpler words would not need to be read twice in order to grasp the idea.

We often rail at the absurdity of legal phraseology. I have just signed a lease which I read with little understanding of some words but assumed it to be highly proper. In writing other than legal documents most lawyers, I imagine, do not use all of the impressive words at their command as many doctors seem impelled to do. I am unfamiliar with legal magazines, but this week I ran across the December number of Bench and Bar, read an article on "The Actual Trial of Cases" by Henry Wollman, became intensely interested in a subject quite apart from my habit of thought and what is more, I understood every sentence and every word. I cannot truthfully say this of most of the medical articles which I read. I wish many doctors might read this legal article or lecture, so plainly written and so interesting to a layman, and then compare it with our average medical literature.

Uncalled for criticism is a dangerous instrument and often does more harm than good, but since I am on the verge of becoming an old man who has given up his hope of revolutionizing dermatology and am well aware that in my contributions to its literature during the past forty years or more the heel of Achilles can be found exposed in very many places, I sincerely trust that Dr. Scholz will not take offense at what is merely intended as a kindly suggestion to him and other younger colleagues.

George Henry Fox, New York.

COMmenr.-In reply to Dr. Scholz' article under the title of Dermatological Misnomers, in the February ARCHIves, in which he criticizes, and by implication would change many old and well established dermatologic names, I would like to quote the following sentences from Barrett Wendell in his work on English Composition:

In English, as in every other language, the final test of what words we may use is inevitably the usage of those who speak and write it; the test of what words we should use is the usage of those who speak and write it best, in other words, good use. . .

Common consent, general practice, is what makes the . . . alphabet signify anything. In this fact lies the... hopelessness of the efforts now and then made by.. . dogmatists, not possessed of despotic authority, to reform spelling. [With equal truth we 
might substitute nomenclature here for spelling.-Ed.] . . . The question in a given instance is not what ought to be the case, but what is. And to the state of things which enables us to decide in spelling, as in other fashions, what the case is at any given moment, we give, for convenience sake, the name "Good Use," . . .

Dictionaries and grammars [or critics in nomenclature.-Ed.] to be sure may codify what exists at any given moment. Regarded as codes, they are invaluable; but at best they are codes of common law, not legislative enactments. The only sanction behind them is that of practice, of usage.

$\mathrm{He}$ is speaking of good usage as it applies to words in general literature. The rules, because they are based on fundamental biologic habits of mankind, apply to good usage of technical words in whatever profession, particularly if it is an old profession like medicine. Words of long established usage have grown so deeply into literature and into the minds of men that they cannot be uprooted. This is accepted as one of the fixed principles of literature in general. It would be well if we familiarized ourselves with these principles and kept them in mind when we feel inclined to make quixotic attacks on dermatologic nomenclature.-ED.] 